Article

\title{
Preliminary Design of a Multi-Column TLP Foundation for a 5-MW Offshore Wind Turbine
}

\section{Yongsheng Zhao *, Jianmin Yang and Yanping He}

State Key Laboratory of Ocean Engineering, Shanghai Jiao Tong University, 800 Dongchuan Road, Shanghai 200240, China; E-Mails: jmyang@sjtu.edu.cn (J.Y.); hyp110@sjtu.edu.cn (Y.H.)

* Authors to whom correspondence should be addressed; E-Mail: yongsheng@sjtu.edu.cn; Tel.: +86-21-34206514; Fax: +86-21-34206701.

Received: 12 August 2012; in revised form: 24 September 2012 / Accepted: 1 October 2012 / Published: 15 October 2012

\begin{abstract}
Currently, floating wind turbines (FWTs) may be the more economical and suitable systems with which to exploit offshore wind energy in deep waters. Among the various types of floating foundations for offshore wind farms, a tension leg platform (TLP) foundation can provide a relatively stable platform for currently available offshore wind turbines without requiring major modifications. In this study, a new multi-column TLP foundation (WindStar TLP) was developed for the NREL 5-MW offshore wind turbine according to site-specific environmental conditions, which are the same as the OC3-Hywind (NREL) conditions. The general arrangement, main structure and mooring system were also designed and investigated through hydrodynamic and natural frequency analyses. The complete system avoids resonance through the rotor excitations. An aero-hydro-servo-elastic coupled analysis was carried out in the time domain with the numerical tool FAST. Statistics of the key parameters were obtained and analysed and comparisons to MIT/NREL TLP are made. As a result, the design requirements were shown to be satisfied, and the proposed WindStar TLP was shown to have favourable motion characteristics under extreme wind and wave conditions with a lighter and smaller structure. The new concept holds great potential for further development.
\end{abstract}

Keywords: floating wind turbine (FWT); offshore wind; tension leg platform; preliminary design; natural frequency analysis 


\section{Introduction}

In recent years, wind power has been the fastest-growing type of renewable energy worldwide, with increasing efforts being concentrated on installing offshore wind turbines with a fixed bottom foundation. However, the existing offshore fixed-bottom technology can only be deployed at a water depth of $50 \mathrm{~m}$ or less [1]. As the technology moves into deeper waters, floating wind turbines (FWTs) may be more economical and suitable for exploiting offshore wind energy in deep water. Currently, there are a number of offshore wind turbine floating foundation concepts in various stages of development. These concepts fall into four main categories: spars, tension leg platforms (TLPs), semi-submersible platforms, and barges.

Henderson et al. [2] have discussed the advantages of utilizing floating support structures and outlined the technical challenges for different types of FWTs. They also provided a detailed overview of the potential new markets for the FWT technology. Wang et al. [3] presented a literature survey of the research and development on FWTs. The authors described various existing conceptual designs and summarized the design principles of these floater concepts. They also gave recommendations for future work. Cordle [4] performed a concise review of current design standards or guidelines relevant to FWTs. Recommendations for possible extensions to the IEC 61400-3 standard were proposed. Nielson et al. [5] carried out integrated dynamic analysis for the Hywind (spar-type) concept. Various environmental conditions and control algorithms were considered. The numerical simulation results were compared with scale-model test results. They observed that the conventional blade pitch controller introduced negative damping when wind velocities were above rated wind speed. The modified controller was shown to be effective in avoiding negative damping for the Hywind concept. Roddier et al. [6] presented a feasibility study conducted for the WindFloat (semi-submersible type) technology. The authors indicated that the design of hull structures for a FWT must take into consideration the design standards developed for oil and gas offshore platforms and offshore wind turbines.

Among the various types of floating foundations for offshore wind farms, TLPs are regarded as one of the leading candidates [7]. Suzuki et al. [7] carried out an initial design of a TLP for a 2.4-MW wind turbine. Numerical analyses under different environmental conditions were performed on the dynamic responses of TLP, tendon tension deviations, natural frequencies and dynamic responses to seismic forces. Ren et al. [8] studied the effect of additional mooring chains on the motion performance of a TLP-type FWT. It was concluded that the combined mooring system could play an active role in reducing the surge motion responses. Matha [9] verified the MIT/NREL TLP design concept via comparisons with frequency-domain calculations. An extensive loads and stability analysis for ultimate and fatigue loads was performed. The author pointed out that the model development and analysis process developed in the study could serve as a blueprint for future analysis of new FWT design concepts. In general, a TLP foundation is vertically constrained by tendons and thus has small dynamic responses to environmental loads. This unique feature provides a relatively stable platform for currently available offshore wind turbines, without requiring major modifications. The key components of an offshore wind turbine mounted on a TLP foundation are described as follows and shown in Figure 1. 
(1) Rotor-Nacelle-Assembly (RNA) system;

(2) Tower structure;

(3) Hull structure, consisting of columns, pontoons and column/pontoon nodes supporting the wind turbine and tendons;

(4) Mooring system consisting of tendons and top/bottom connectors;

(5) Foundation system consisting of templates with bottom tendon connectors and (typically) tension piles or gravity anchors.

Figure 1. Configuration of an offshore wind turbine with a mono-column TLP foundation.

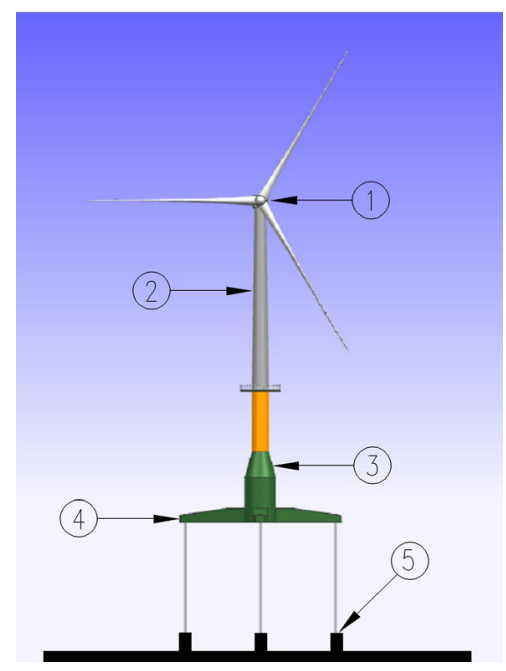

Because the exploration of deep water wind energy is a relatively new field, the design of a TLP foundation that is suitable for an offshore wind turbine presents several challenges. Generally, there are three fundamental challenges: (1) the design of the multi-body system, including the TLP platform, tower, and RNA, should avoid resonance with wind and waves, as well as any turbine-induced loads; (2) the determination of the aero-hydro-servo-elastic loads and their coupled responses; and (3) the design of the tendon system, which should have sufficient pre-tension to balance large overturning moments and to prevent slack lines, while remaining soft or compliant in surge, sway, and yaw conditions [10]. Other challenges include the lack of standards, rules, guidelines, experimental data, and industrial experience specific to floating offshore wind turbines.

In this paper, we attempt to address these challenges and provide a technically feasible solution for exploring deep water wind energy. There are three main parts in the current study. The first part discusses the relevant design basis, including site-specific environmental conditions, design requirements, and wind turbine properties. The second part provides a general description of our new multi-column TLP design concept (WindStar TLP), including the general arrangement and dimensions, main structure, and tension mooring system. The final part concentrates on hydrodynamic properties, the natural frequency analysis and the full-coupled dynamic response simulations. The effects of an elastic turbine system and TLP floater on the prediction of the natural frequencies of the FWT are investigated. In addition, a comparative analysis is carried out of two TLP systems: WindStar TLP and MIT/NREL TLP. In summary, the preliminary WindStar TLP design proposed here will 
contribute to the understanding of the important aspects of an initial design process, and the concept holds potential for further development.

\section{Design Basis}

\subsection{Design Requirements}

To ensure the safety and competitiveness of the WindStar TLP, the following requirements are considered [7,10]:

a. It must be able to support a 5-MW offshore wind turbine.

b. It must ensure that the high-energy excitation frequencies do not coincide with the natural frequency of the entire system.

c. It must offer sufficient rigidity to the wind turbine to withstand dynamic loads during operation.

d. It must operate for a design life of at least 20 years and must survive the 50 -year return wind and wave loading.

e. Its inclination angle must not exceed $5^{\circ}$ during either normal operation or extreme conditions.

f. The tendon tension must always be positive, and sufficient safety margins should always be maintained for the tendon force. The safety factor should be no less than 3.0.

g. It must allow adequate access for maintenance.

\subsection{Site Location and Environmental Conditions}

Designing a suitable foundation for an offshore wind turbine is a highly site-specific process. This study utilises the same location as the referenced studies [11,12], which were carried out at a site located at $61^{\circ} 20^{\prime} \mathrm{N}$ latitude and $0^{\circ} 0^{\prime} \mathrm{E}$ longitude, near the Shetland Islands, northeast of Scotland (UK).

\subsubsection{Water Depth}

The water depth at the assumed installation site is $160 \mathrm{~m}$ below Mean Sea Level (MSL).

\subsubsection{Water Levels}

There is not a sufficient amount of water level data for the chosen site, so we adopted the IJmuiden site values for this study [13]. The following extreme values from 22 years of measured data were used (see Table 1).

Table 1. Measured water levels at the IJmuiden site.

\begin{tabular}{cc}
\hline Water levels & Values \\
\hline Highest still water level (HSWL) & $+2.4 \mathrm{~m} \mathrm{MSL}$ \\
Mean sea level (MSL) & $0 \mathrm{~m}$ \\
Lowest still water level (LSWL) & $-2.1 \mathrm{~m} \mathrm{MSL}$ \\
\hline
\end{tabular}




\subsubsection{Currents}

The values of currents are taken from the Noordzeewind OWEZ project [13], which was located relatively close to the selected location. For the normal current model (NCM, [14]) an average value of $0.6 \mathrm{~m} / \mathrm{s}$ is used and for the extreme current model (ECM, [14]) a $1.2 \mathrm{~m} / \mathrm{s}$ one, respectively, at the surface level.

\subsubsection{Wind and Wave Parameters}

It was assumed that the wind and wave parameters are described by a 10-minute average wind speed, $V$, at the hub height, significant wave height, $H_{S}$, and peak spectral period, $T_{P}$. The joint-probability distribution is provided in terms of 37,992 samples, representing a total of approximately 13 years of data. The cumulative distribution function of the mean wind speed at the hub height is shown in Figure 2, and the joint probability distributions for $H_{S}$ and $T_{P}$ at a given mean wind speed $\left(V_{h u b}=11.4 \mathrm{~m} / \mathrm{s}\right)$ are shown in Figure 3.

Figure 2. Cumulative distribution function of mean wind speed at the hub height.

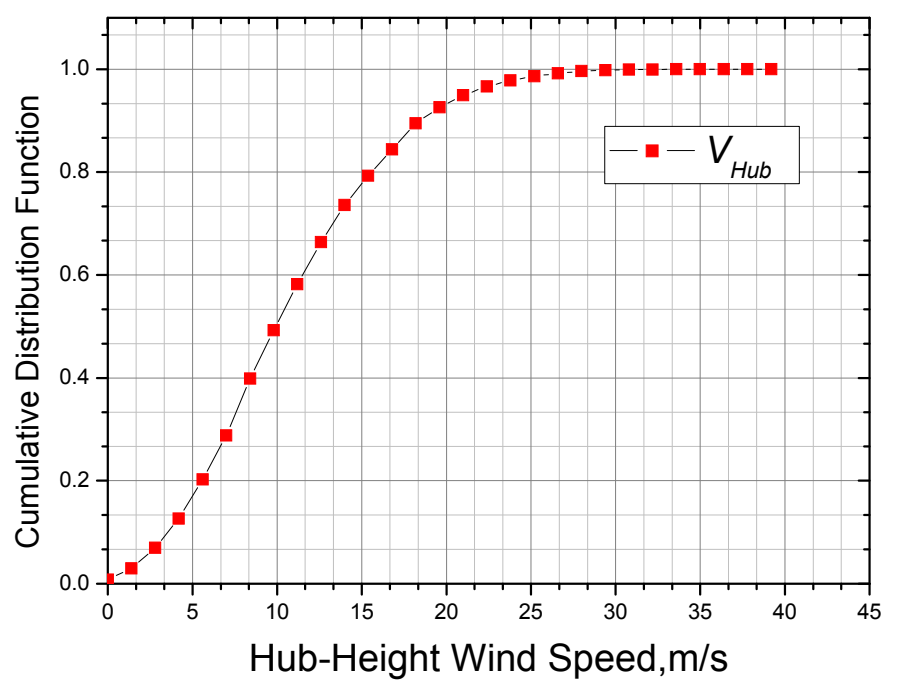

Figure 3. 3D bar plot of $H_{S} v s . T_{P}\left(V_{h u b}=11.4 \mathrm{~m} / \mathrm{s}\right)$.

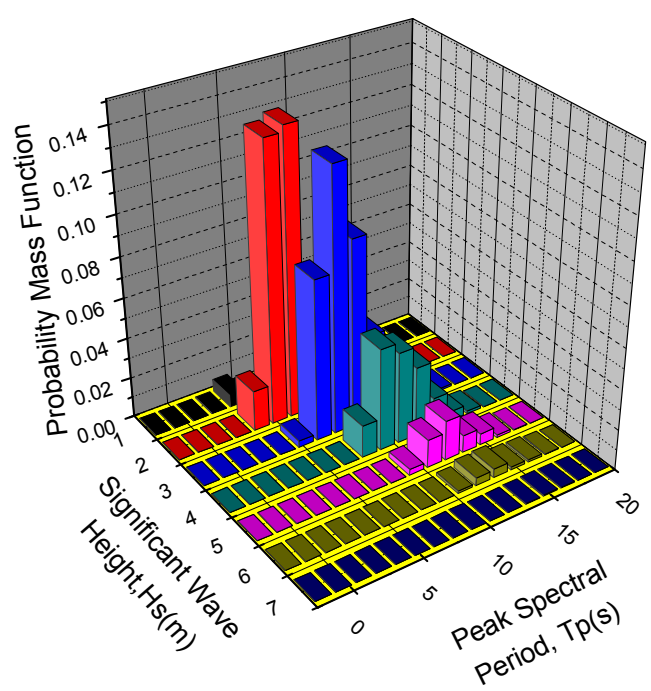


Based on a three-hour reference period, the significant wave height with a return period of 1 year, $H_{S 1}$, is $10.8 \mathrm{~m}\left(15.5 \mathrm{~s}<T_{P}<19.7 \mathrm{~s}\right)$, and the significant wave height with a return period of 50 years, $H_{S 50}$, is $13.8 \mathrm{~m}\left(18.5 \mathrm{~s}<T_{P}<19.9 \mathrm{~s}\right)$. Based on a 10 -minute averaging period, the reference wind speed at the hub height with return periods of 1 year, $V_{1}$, and 50 years, $V_{50}$, was measured as 40 and $50 \mathrm{~m} / \mathrm{s}$, respectively, as provided in Jonkman [11].

\subsection{Wind Turbine RNA and Tower Specifications}

The NREL offshore 5-MW baseline wind turbine model, which is representative of utility-scale multi-megawatt turbines, was considered in this study. The model is a conventional three-bladed upwind variable-speed, variable blade-pitch-to-feather-controlled turbine [15]. Figure 4 shows the main dimensions (in millimetres) of the turbine RNA. The nacelle size was taken from the Repower 5-MW turbine. Table 2 summarises the main technical specifications of this turbine.

Figure 4. RNA of the NREL 5-MW baseline offshore wind turbine.

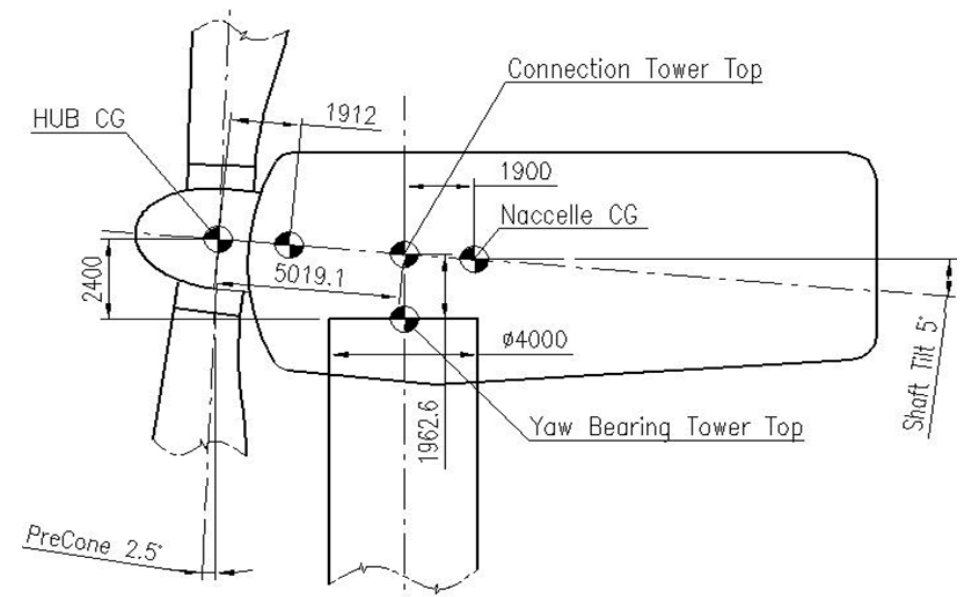

Table 2. Properties of the NREL offshore 5-MW baseline wind turbine.

\begin{tabular}{ccc}
\hline Items & Units & Specifications \\
\hline Rotor, hub diameter & $\mathrm{m}$ & 126,3 \\
Cut-in, rated, cut-out wind speed & $\mathrm{m} / \mathrm{s}$ & $3,11.4,25$ \\
Cut-in, rated rotor speed & $\mathrm{rpm}$ & $6.9,12.1$ \\
Overhang, shaft tilt, precone & $\mathrm{m}, \mathrm{deg}, \mathrm{deg}$ & $5,5,2.5$ \\
Rotor mass & $\mathrm{kg}$ & 110,000 \\
Nacelle mass & $\mathrm{kg}$ & 240,000 \\
Nacelle size (length, width, height) & $\mathrm{m}$ & $19,6,7$ \\
\hline
\end{tabular}

The turbine tower is installed on the top of the centre column by welding. Its diameter was slightly enlarged compared with the reference structure [13]. The revised tower section properties are summarised in Table 3 . The overall structural weight is approximately $230 \mathrm{t}$, with the gravity centre at a height of $28.5 \mathrm{~m}$ from the tower base. 
Table 3. Turbine tower section properties.

\begin{tabular}{cccc}
\hline Elevation $(\mathbf{m})$ & Outer Diameter $(\mathbf{m})$ & Thickness $(\mathbf{m})$ & Point Mass $(\mathbf{k g})$ \\
\hline 21.3 (Tower base) & 6.000 & 0.032 & - \\
33.3 & 5.634 & 0.030 & - \\
45.3 & 5.267 & 0.028 & - \\
57.3 & 4.902 & 0.026 & 1400 \\
69.3 & 4.537 & 0.024 & - \\
81.3 & 4.171 & 0.022 & - \\
86.9 (Yaw bearing) & 4.000 & 0.030 & 1000 \\
\hline
\end{tabular}

\section{WindStar TLP Concept Description}

\subsection{General Arrangement and Main Dimensions}

The WindStar TLP features one central column, with three radiating corner columns and pontoons. As shown in Figure 5, the turbine also includes three tendon support structures (TSS), three equivalent groups of tendons attached to the end of each external pontoon, and a gravity anchor (not shown) that is mechanically connected to the bottom of each tendon through bottom connectors. The WindStar TLP has the ability to be integrated at the fabrication yard and towed to the installation site with specially designed temporary buoyancy modules (TBM).

Figure 5. Configuration of the WindStar TLP: (a) Normal Operation; (b) Wet tow.

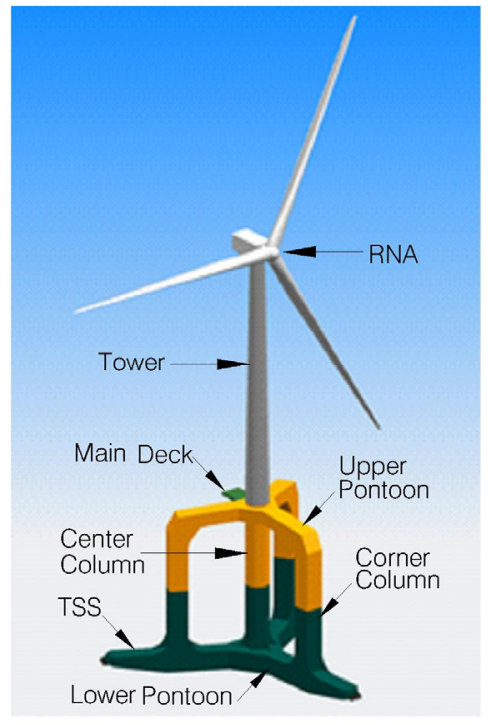

(a)

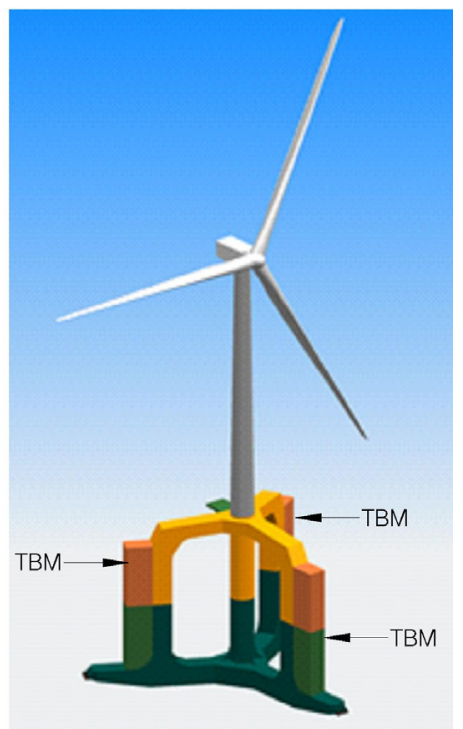

(b)

To transfer the large wind overturning moment more effectively, the turbine tower is directly mounted on the centre column, which is essentially an extension of the tower and has the same diameter as the tower base diameter. Therefore, the structural continuity is realised, and the stress concentration can be minimised at this crucial area. Three corner columns provide external stability during operation, wet tow transportation, installation, and tendon removal.

Two groups of horizontal pontoons are designed to connect the three corner columns with the centre column. The upper and lower pontoons are designed as box-type structures, and the corner 
columns/pontoon node is strengthened. Three tendon support structures (TSS) are employed to support the tendons and reduce the dynamic tendon tensions. The mooring system is composed of three equivalent groups of tendons, which utilise three polyester ropes. A relatively large main deck platform is positioned around the centre column on top of the upper pontoons. There is sufficient distance between the main deck and the highest wave crest elevation to prevent potential wave impact damage.

Based on a thorough investigation of the corner column dimensions, the distance between the centre column and corner columns, and the lower pontoon dimensions using the frequency domain method, the general arrangement and main dimensions are as shown in Figure 6, and the principal parameters are provided in Table 4.

Figure 6. General arrangement of the WindStar TLP system: (a) Front view; (b) Side view; (c) Top view.

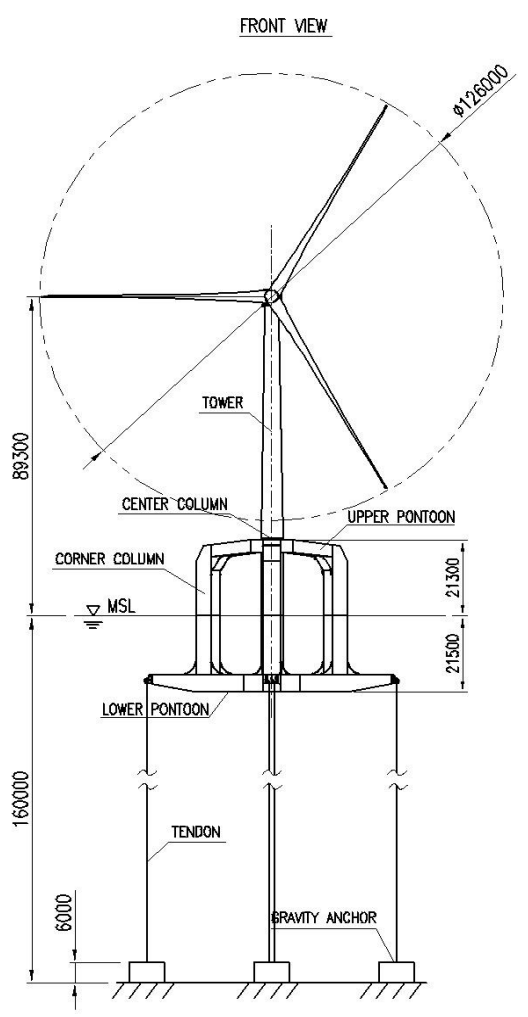

(a)

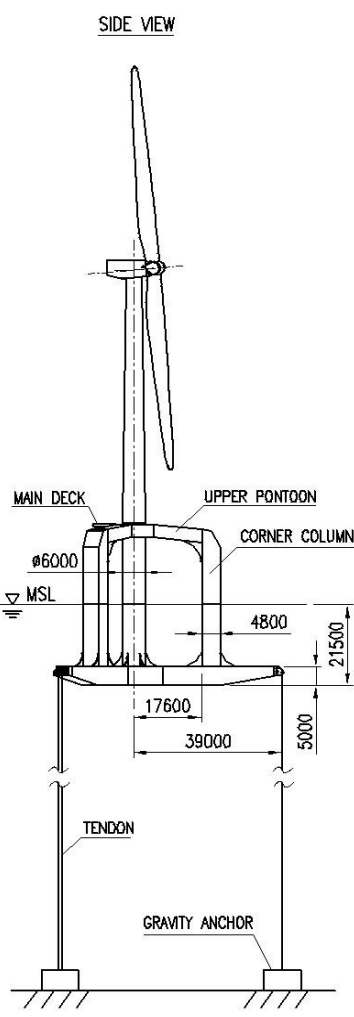

(b)

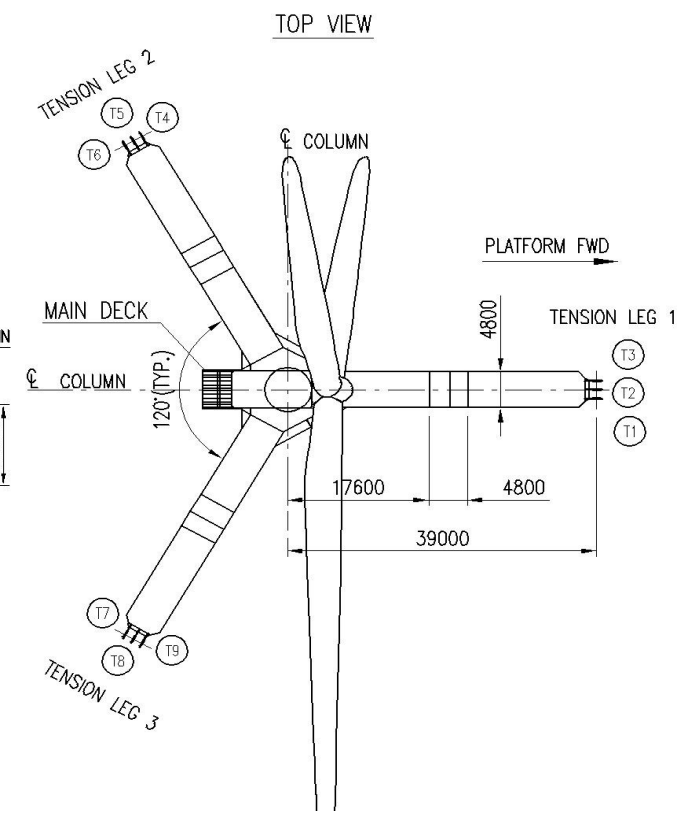

(c)

Table 4. Principal parameters of the WindStar TLP.

\begin{tabular}{cc}
\hline Items & Parameters \\
\hline Centre column diameter $(\mathrm{m})$ & 6.0 \\
Corner column section dimension $(\mathrm{m})$ & $4.8 \times 4.8$ \\
Distance between the centre column and corner column $(\mathrm{m})$ & 20.0 \\
Moulded depth $(\mathrm{m})$ & 42.8 \\
Design draft $(\mathrm{m})$ & 21.5 \\
Air gap distance $(\mathrm{m})$ & 21.3 \\
Platform mass (including outfitting) $(\mathrm{t})$ & 1770.0 \\
Platform mass vertical centre (measured from keel) $(\mathrm{m})$ & 9.85 \\
Pretension $(\mathrm{t})$ & 1950.0 \\
Total Displacement $(\mathrm{t})$ & 4275.0 \\
\hline
\end{tabular}




\subsection{Structural Design and Weight Estimate}

The structural design of the WindStar TLP concept mainly consists of columns, pontoons, and column/pontoon nodes. The TLP hull is a fully welded steel structure that consists of high-tensile steel with a minimum yield stress of $355 \mathrm{MPa}$.

The preliminary structural layout is shown in Figure 7. The centre column has an inner shaft structure. The inner shaft is a cylinder with no compartmentalisation from the top to the bottom of the column. The annulus between the outer hull and inner shaft is vertically separated into three compartments by two horizontal, watertight bulkheads. The lower annulus of each column serves as a ballast tank. The inclined upper pontoon is designed to withstand wave loads.

Figure 7. Structural layout of the WindStar TLP.

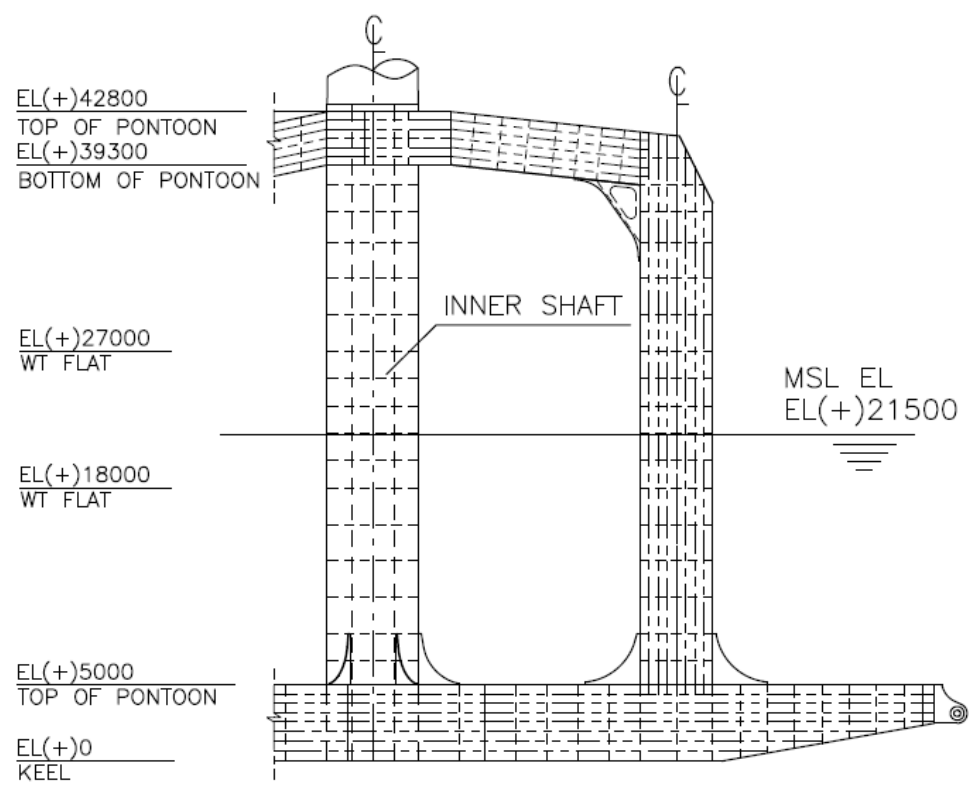

The initial scantling of columns and pontoons is performed based on API Bulletin 2U (2004) [16] and ABS MODU rules (2012) [17]. The outer shell of the centre column is stiffened with equally spaced ring girders to provide sufficient stiffness against bulking failure. The flat structures, including corner columns, column tops/bottoms, pontoon tops/bottoms and bulkheads, are sized according to the largest design heads.

The scantling result shows that the present hull structural weight is approximately $1200 \mathrm{t}$, with a vertical gravity centre height located $18 \mathrm{~m}$ above the keel. Some additional space is included to take into account the weights of the deck equipment, landing platform, stairs, and piping system. A detailed structural model of the WindStar TLP hull is shown in Figure 8. 
Figure 8. FE model of the WindStar TLP hull, showing both the outer shell and inner structure.

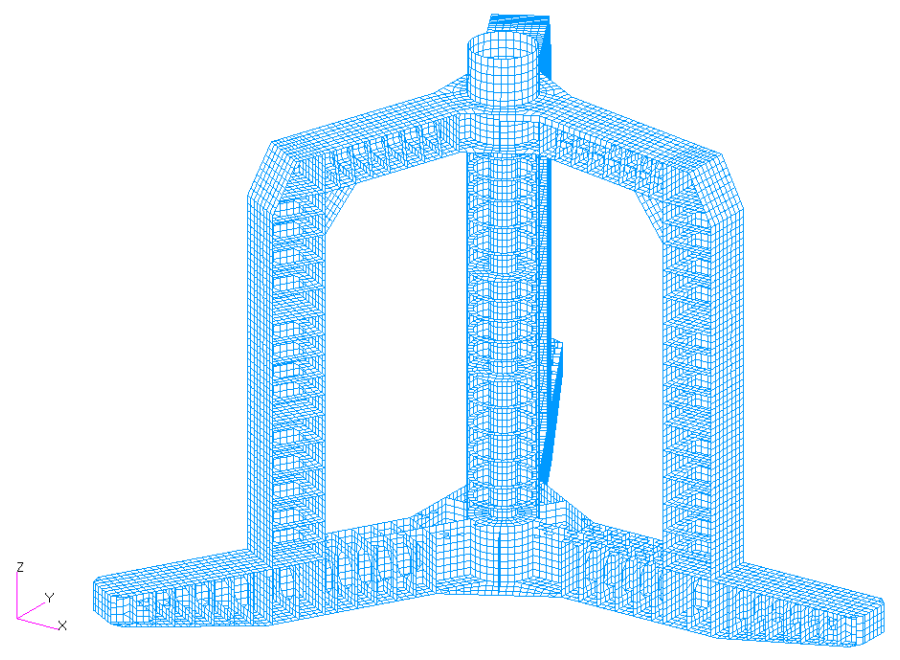

\subsection{Mooring System Properties}

The mooring system consists of three equivalent groups of tendons, and each tendon pretension is set to be $650 \mathrm{t}$. Three polyester ropes are adopted for each tendon due to the low axial stiffness and relatively high minimum breaking load of the tendons. This characteristic is helpful to prevent the supporting platform's natural frequencies from coinciding with the third rotor harmonics. The principal properties of the tendon ropes are shown in Table 5.

Table 5. Principal properties of the tendon ropes [18].

\begin{tabular}{ccccc}
\hline $\begin{array}{c}\text { Diameter } \\
(\mathbf{m m})\end{array}$ & $\begin{array}{c}\text { Min. breaking } \\
\text { load (t) }\end{array}$ & $\begin{array}{c}\text { Axial stiffness } \\
\text { EA (MN) @ } \mathbf{1 0 \%} \mathbf{- 3 0} \% \mathbf{~ M B L}\end{array}$ & $\begin{array}{c}\text { Weight in air } \\
(\mathbf{k g} / \mathbf{m})\end{array}$ & $\begin{array}{c}\text { Weight in } \\
\text { water } \mathbf{( k g / m})\end{array}$ \\
\hline 239.0 & 1967.0 & 372.0 & 36.1 & 9.29 \\
\hline
\end{tabular}

For small displacements (small angle assumption), the restoring coefficients of the selected mooring system are determined by the following Equations [19]:

$$
\begin{gathered}
C_{11}=C_{12}=\frac{F_{\text {tether }}}{L_{\text {tether }}} \\
C_{33}=\frac{3 E_{\text {tether }} A_{\text {tether }}}{L_{\text {tether }}} \\
C_{44}=C_{55}=\frac{3 E_{\text {tether }} A_{\text {tether }}}{2 L_{\text {tether }}}\left(L_{\text {fairlead }}\right)^{2} \\
C_{66}=\frac{F_{\text {tether }}}{L_{\text {tether }}}\left(L_{\text {fairlead }}\right)^{2}
\end{gathered}
$$

where:

$F_{\text {tether }}=$ total pretension at the fairlead of the mooring system, $1950 \mathrm{t}$;

$L_{\text {tether }}=$ total length of the tether, $134 \mathrm{~m}$; 
$E_{\text {tether }} A_{\text {tether }}=$ axial stiffness of the tether, $1116 \mathrm{MN}$;

$L_{\text {fairlead }}=$ distance from the fairlead to the platform centre, $39 \mathrm{~m}$.

By applying the aforementioned equations and given parameters, the restoring coefficients of the mooring system are obtained, as shown in Table 6 . The restoring coefficients of the mooring system, together with hydrostatics, are useful for predicting the natural periods of the system.

Table 6. Restoring coefficients of the mooring system.

\begin{tabular}{cccc}
\hline $\begin{array}{c}\text { Surge (Sway) } \\
\text { restoring coefficient } \\
\mathbf{C}_{\mathbf{1 1}}(\mathbf{k N} / \mathbf{m})\end{array}$ & $\begin{array}{c}\text { Heave } \\
\text { restoring coefficient } \\
\mathbf{C}_{\mathbf{3 3}}(\mathbf{k N} / \mathbf{m})\end{array}$ & $\begin{array}{c}\text { Roll (Pitch) } \\
\text { restoring coefficient } \\
\mathbf{C}_{\mathbf{4 4}}(\mathbf{k N . m} / \mathbf{r a d})\end{array}$ & $\begin{array}{c}\text { Yaw } \\
\text { restoring coefficient } \\
\mathbf{C}_{\mathbf{6 6}}(\mathbf{k N . m} / \mathbf{r a d})\end{array}$ \\
\hline 145.6 & $2.5 \times 10^{4}$ & $1.9 \times 10^{7}$ & $2.67 \times 10^{5}$ \\
\hline
\end{tabular}

\section{Hydrodynamic Characteristics}

To calculate the hydrodynamic characteristics of the WindStar TLP, the SESAM/Wadam software program was applied in this study [20]. The software uses the three-dimensional boundary integral equation method to solve the linearized hydrodynamic radiation and diffraction problems for the interaction of free surface waves with zero-forward-speed floating structures in the frequency domain. According to the geometric symmetry of the supporting platform, four different wave directions, $0^{\circ}$, $15^{\circ}, 30^{\circ}$, and $45^{\circ}$, were selected to perform the hydrodynamic analysis. The panelised view of the WindStar TLP wetted hull and the definition of the coordinate system are shown in Figure 9. The added mass properties in the surge, sway, and heave directions are shown in Figure 10. With three large pontoons, the heave added mass has an average value of $3.53 \times 10^{6} \mathrm{~kg}$ and varies less with frequency. However, the added mass in surge and sway tend to decrease with increasing frequency. The computed added-mass and damping coefficients, as well as the wave excitation forces, are used as inputs to the fully coupled time-domain simulation program FAST [21]. Figure 11 presents heave and pitch RAOs for WindStar TLP calculated both in frequency domain (Wadam) and in time domain (FAST with elastic and rigid turbine). The RAOs obtained in FAST with rigid turbine are in good arrangement with Wadam RAOs. This model consistency ensures the accuracy of the following load analysis in FAST. As depicted in the figure, the turbine elasticity has minor effect on the heave resonant response.

Figure 9. Hydrodynamic model of the WindStar TLP wetted hull.

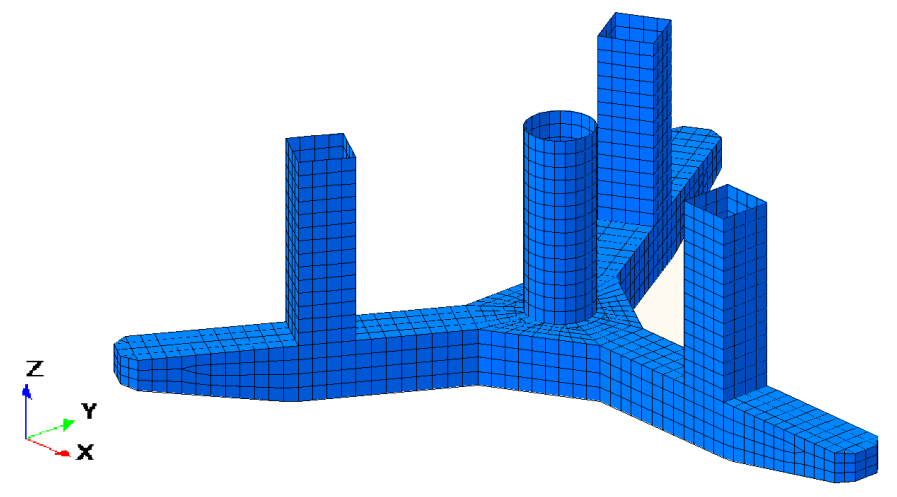


Figure 10. Hydrodynamic added mass of the WindStar TLP in the translational modes.

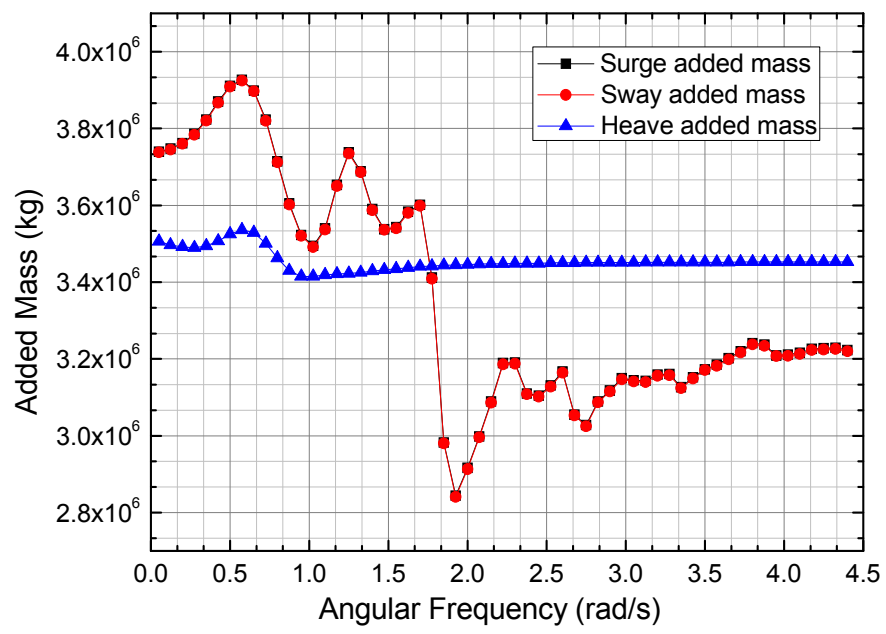

Figure 11. WindStar TLP RAOs: (a) Heave response; (b) Pitch response.

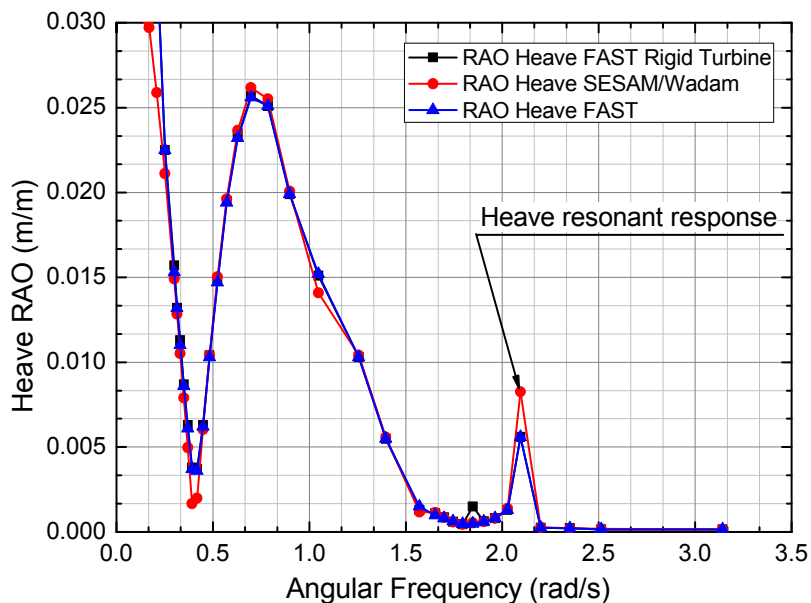

(a)

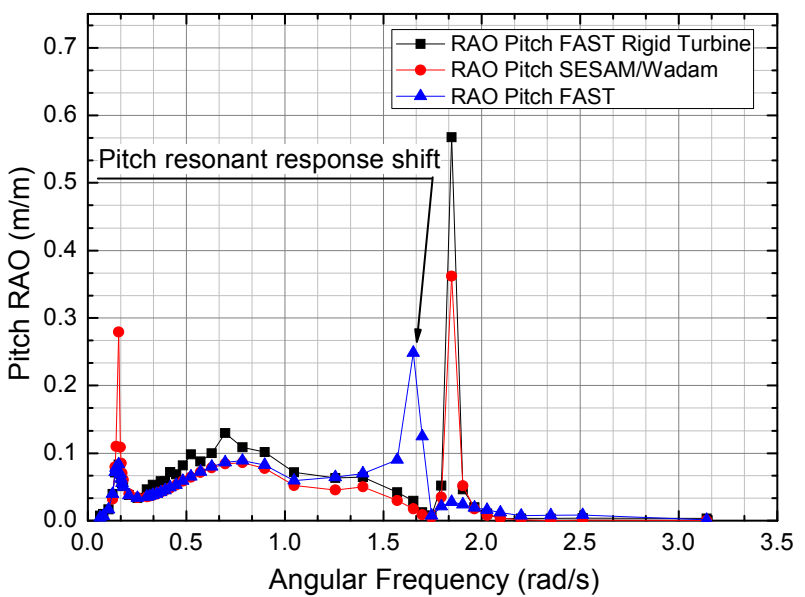

(b)

However, with flexible turbine, the pitch natural frequency is shifted from $1.84 \mathrm{rad} / \mathrm{s}$ to $1.65 \mathrm{rad} / \mathrm{s}$. The shift pitch natural frequency primarily due to the turbine elasticity consists of the positive platform pitch with positive 1 st tower fore-aft deflection mode and vice versa [22]. This result is further compared with a fully-flexible model including platform elasticity by FE methods in the following section.

\section{Natural Frequency Analysis}

The natural frequencies of the entire system are crucial to the performance of the system because they determine the dynamic behaviour of the floating offshore wind turbine, particularly for turbines with TLP-type foundations. The full system should avoid resonance with both the environmental and turbine-induced excitations. For the NREL offshore 5-MW baseline wind turbine, the cut-in and rated rotational speeds of the rotor are 6.9 and $12.1 \mathrm{rpm}$, respectively. Therefore, the first rotor frequency (1-P) ranges from 0.115 to $0.202 \mathrm{~Hz}$, and the corresponding blade-passing frequency ranges from 0.345 to $0.606 \mathrm{~Hz}$ [13]. The natural frequencies of the Windstar TLP in heave, pitch and roll are chosen to be between the 1-P and 3-P rotation frequency intervals, and the natural frequencies for the tower's first bending mode are chosen to be above the 3-P rotation frequency due to its high coupling 
with the platform pitch mode. With the MSC/NASTRAN program [23], the complete WindStar TLP structural model is used to perform eigenanalysis, in which the rotor mass and hydrodynamic added mass are modelled as lump masses with rotational inertia. From this analysis, important natural frequencies are obtained. The relevant results are shown in Table 7, and the Campbell diagram for the WindStar TLP is plotted in Figure 12. Compared to natural frequencies obtained in the previous section, the heave natural frequency moves from $0.334 \mathrm{~Hz}$ to $0.303 \mathrm{~Hz}$, the pitch natural frequency shifts from $0.263 \mathrm{~Hz}$ to $0.248 \mathrm{~Hz}$. The shifted natural frequency in heave mode is mainly because of the up-down deflection mode of TSS. However, the downshifting natural frequency in pitch mode is largely due to the fore-aft deflection mode of the overall platform. This reveals that the importance of the platform elasticity on predicting the complete system natural frequencies, especially for the TLP-type floating wind turbines. There is more than an approximately $10 \%$ safety margin from the rotor excitation frequency boundaries. Figure 13 shows the FE results of the natural frequencies in the pitch mode, 1 st tower fore-aft mode, and 2nd tower fore-aft mode.

Table 7. Natural frequencies of the WindStar TLP.

\begin{tabular}{cc}
\hline Mode & Natural Frequency $(\mathbf{H z})$ \\
\hline Platform Surge/Sway & 0.024 \\
Platform Yaw & 0.049 \\
Platform Heave & 0.303 \\
Platform Pitch & 0.248 \\
Platform Roll & 0.247 \\
1st Tower Side-Side & 0.664 \\
1st Tower Fore-Aft & 0.673 \\
2nd Tower Side-Side & 1.886 \\
2nd Tower Fore-Aft & 2.079 \\
\hline
\end{tabular}

Figure 12. Campbell diagram of the WindStar TLP.

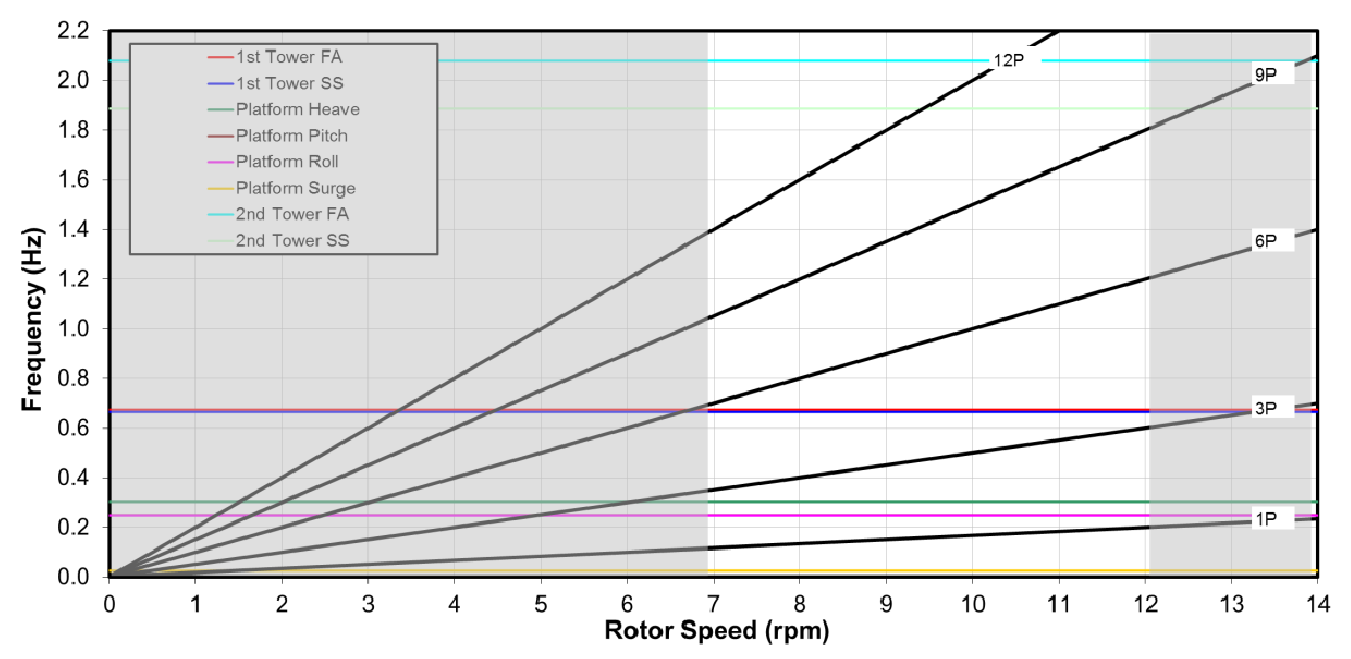


Figure 13. Mode shapes and natural frequencies of the WindStar TLP system: (a) Heave mode; (b) Pitch mode; (c) 1st Tower Fore-Aft mode; (d) 2nd Tower Fore-Aft mode.

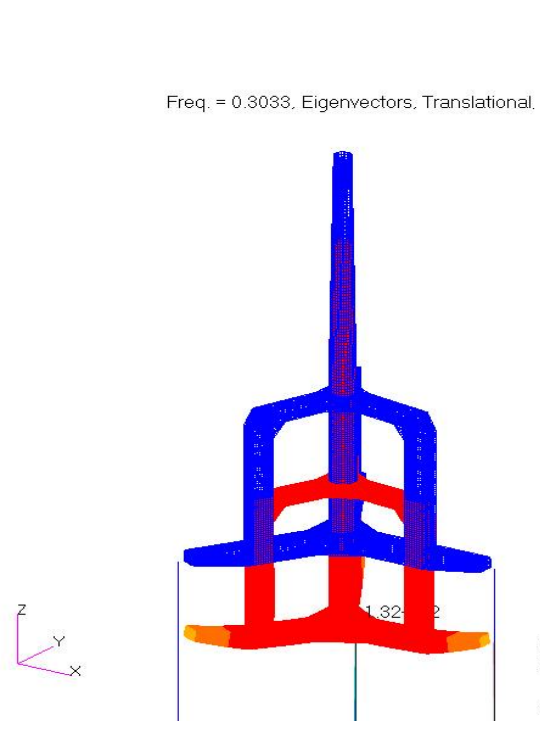

(a)

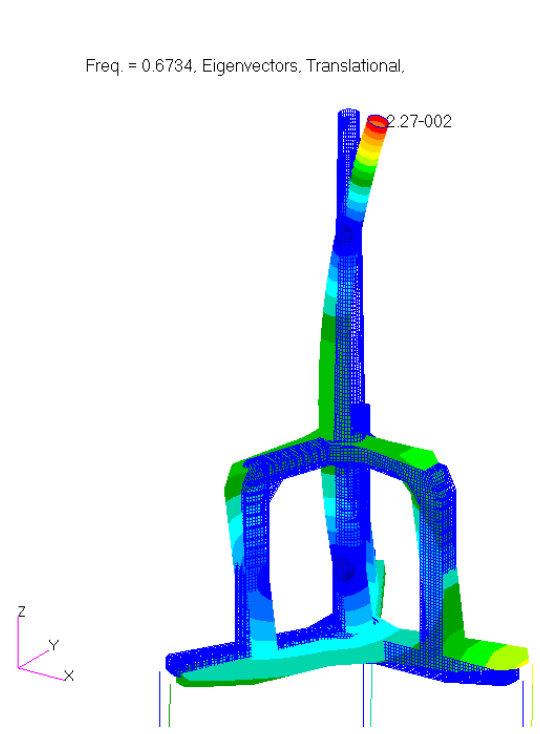

(c)
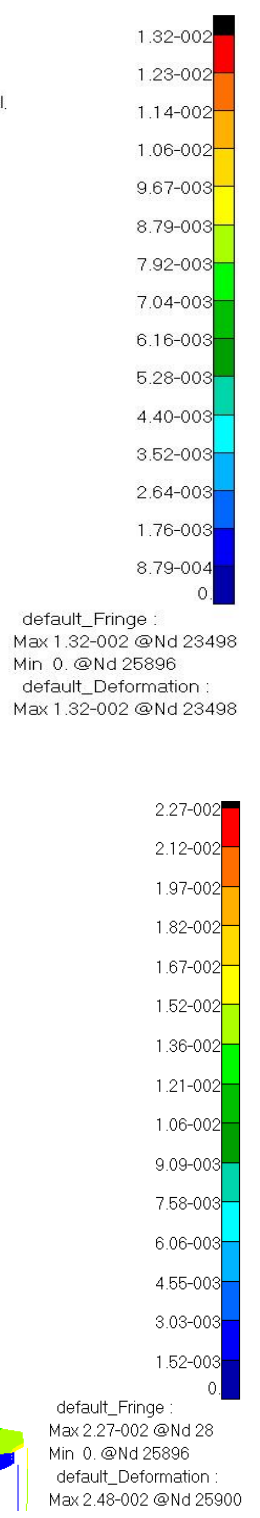

248-002@Nd 25900

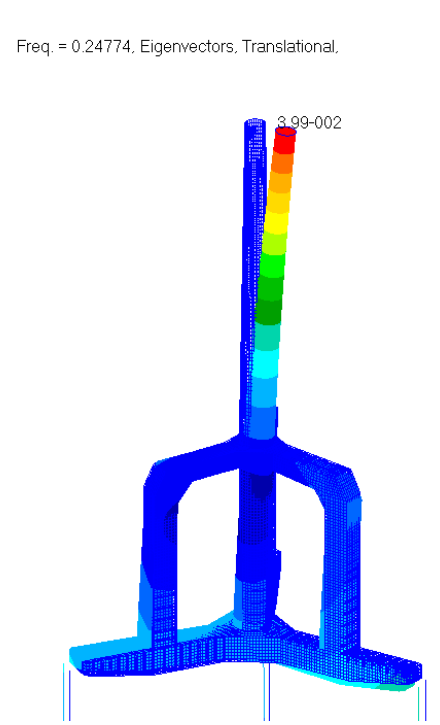

(b)
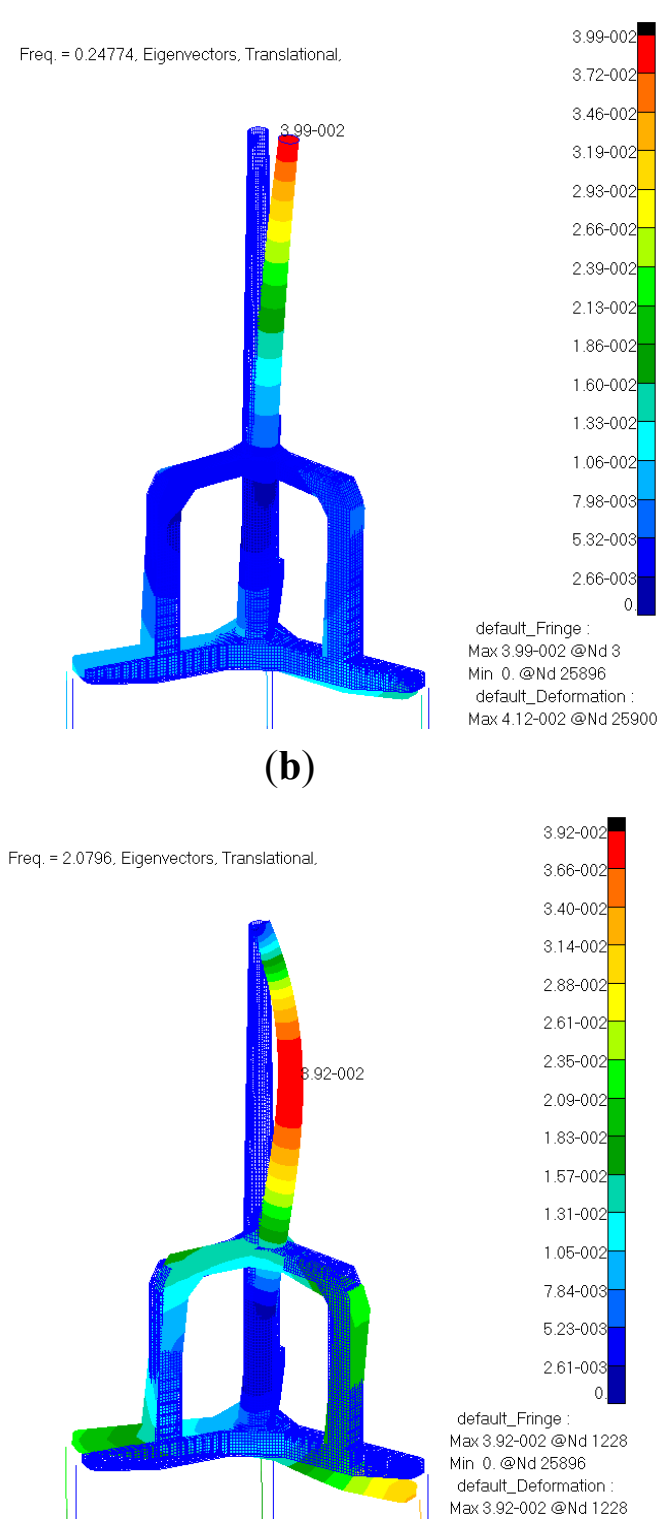

(d)

\section{Dynamic Response Simulations}

The IEC 61400-3 design standard [14] was chosen as the load analysis guideline in this study. This standard is largely limited to offshore, fixed-bottom support structures. For the preliminary load analysis, only a few DLCs (Table 8) were selected. DLC 1.3 considers power production under normal operation over a range of wind speeds and wave conditions. DLC 6.1a and 6.3a consider parked (idling) conditions under extreme 1- and 50-year return periods. For DLC 1.3, the wind speed range is indicated from cut-in to cut-out, and the width of the bins is chosen to be $1.4 \mathrm{~m} / \mathrm{s}$ for the discrete values of $V_{h u b}$ centred (i.e., discrete values of $4.2,5.6, \ldots, 23.8 \mathrm{~m} / \mathrm{s}$ ). For each wind speed, the expected value of the significant wave height is then chosen, $H_{S}=E\left[H_{S} \mid V_{h u b}\right]$. The peak spectral period, $T_{P}$, is then selected by the same method used to determine the expected value at the given wind speed and the significant wave height, $T_{P}=E\left[T_{P} \mid H_{S}, V_{h u b}\right]$. Winds and waves are considered collinear. 
Table 8. Summary of the selected design load cases.

\begin{tabular}{ccccccc}
\hline \multirow{2}{*}{ DLC } & \multicolumn{2}{c}{ Winds } & \multicolumn{2}{c}{ Waves } & Currents & \multirow{2}{*}{ Events } \\
\cline { 2 - 5 } & Model & Speed & Model & Height & Model & \\
\hline 1.3 & ETM & $V_{\text {in }}<V_{h u b}<V_{\text {out }}$ & NSS & $H_{S}=E\left[H_{S} \mid V_{h u b}\right]$ & NCM & \multirow{2}{*}{ Normal operation } \\
$6.1 \mathrm{a}$ & EWM & $V_{h u b}=0.95 \times V_{50}$ & ESS & $H_{S}=1.09 \times H_{S 50}$ & ECM & Yaw $=0^{\circ}$ \\
$6.3 \mathrm{a}$ & EWM & $V_{h u b}=0.95 \times V_{1}$ & ESS & $H_{S}=1.09 \times H_{S 1}$ & ECM & Yaw $=0^{\circ}$ \\
\hline
\end{tabular}

For DLC 1.3, each discrete wind speed event simulation is 10 minlong. The other simulations for DLC 6.1a and 6.3a last one hour. Turbulent-wind inflow is provided by the computer program Turbsim [24], followed by a turbine response simulation using FAST [21]. To ensure an apples to apples comparison, the MIT/NREL TLP concept is selected and compared with the WindStar TLP for all the selected load cases. Both TLP systems use the same wind turbine specifications, metocean parameters, and control systems. The latter is also the same as in the land-based system [11]. The MIT/NREL TLP is a mono-column TLP supporting the NREL-5MW wind turbine. The TLP hull has a diameter of $18 \mathrm{~m}$ and is ballasted with concrete to provide stability during wet tow operations. Its mooring system consists of a total of eight tendons supported at the end of the TSS (two at each end) with a fairlead radius of $27 \mathrm{~m}$. The hull displacement is $12,485 \mathrm{t}$ and the total pretension is $3206 \mathrm{t}$. The hub height was revised to be the same as the WindStar TLP $(89.3 \mathrm{~m})$. Design specification details are available in Matha [9]. Time series data and global response statistics, including platform surge and pitch, tendon tension, and tower top acceleration, are investigated. In Figure 14, the global responses under the power production conditions (DLC 1.3) are further compared with those under parked conditions (DLC 6.1a and 6.3a). Both designs show the same trend with wind speeds. All of the maximum and minimum responses of the selected parameters are found to be dominated by DLC 6.1a, whereas a larger surge response is generated for the rated wind speed compared with the cut-out wind speed in the power production condition (DLC 1.3a) because of the function of control. In general, the WindStar TLP system has larger dynamic responses than the MIT/NREL TLP system, as shown in Figure $14 \mathrm{a}-\mathrm{c}$. This is mainly because the MIT/NREL TLP concept has larger restoring coefficients and initial pretension, as well as mass properties, thus introducing more resistance to platform movement, as distinguished in Figure 14d. The peak responses of the platform pitch and tower top acceleration follow the same trend of increasing with increased wind speeds. Figure $14 \mathrm{e}$ clearly illustrates the wind and wave effects on tower top acceleration, and it can be concluded that the response is dominated by the wave loads. The tendon tension ratio of the two systems (tension leg 1) is compared in Figure 14f. The tension ratio is defined as:

$$
\operatorname{Tr}_{\max (\operatorname{mean}, \min )}=T_{\max (\operatorname{mean}, \min )} / T_{\text {pre }}-1
$$

where $T r_{\max (m e a n, \min )}, T_{\max (\operatorname{mean}, \min )}$ and $T_{\text {pre }}$ are the maximum (mean, minimum) tension ratio, maximum (mean, minimum) tendon tension and initial pretension, respectively. Compared to the MIT/NREL TLP, the WindStar TLP has a smaller tendon tension ratio in all wind speeds. This indicates that the mooring system of the MIT/NREL TLP is more susceptible to fatigue than that of the WindStar TLP. Under the extreme conditions (DLC 6.1a), the maximum pitch angle of the WindStar TLP is approximately $0.66 \mathrm{deg}$, which is less than the limiting angle of $5 \mathrm{deg}$; the maximum tendon tension value (rope 1) is approximately $347.6 \mathrm{t}$, including the initial pretension. This value gives a safety factor 
of 5.7, which is more than the required value of 3.0. The tendon tension remains positive under the conditions considered. Thus, all of the selected parameters of the WindStar TLP conformed to the design requirements.

Figure 14. (a) Platform surge vs. wind speed; (b) Platform pitch vs. wind speed; (c) Comparisons of two TLP systems; (d) Tower top acceleration vs. wind speed; (e) Wind and wave effect on tower top acceleration; (f) Tendon ratio $v s$. wind speed.

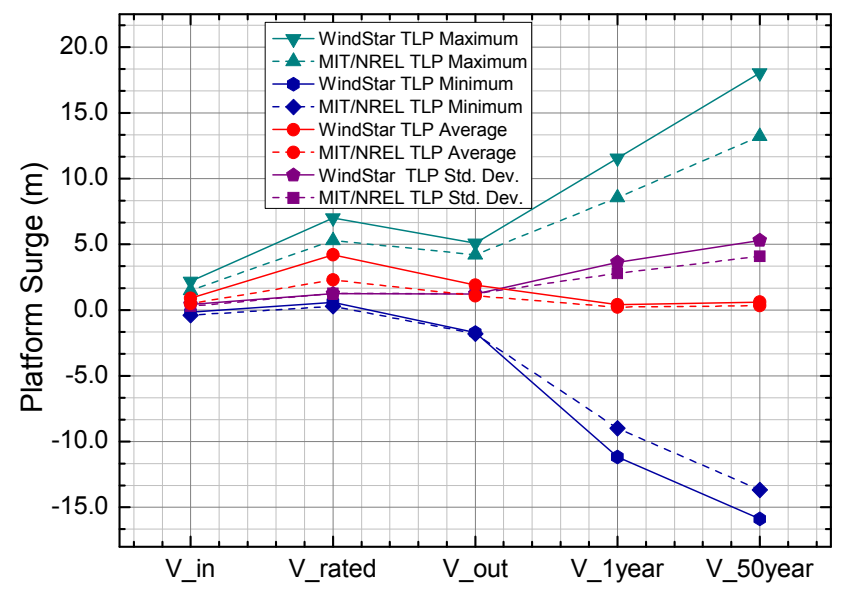

(a)

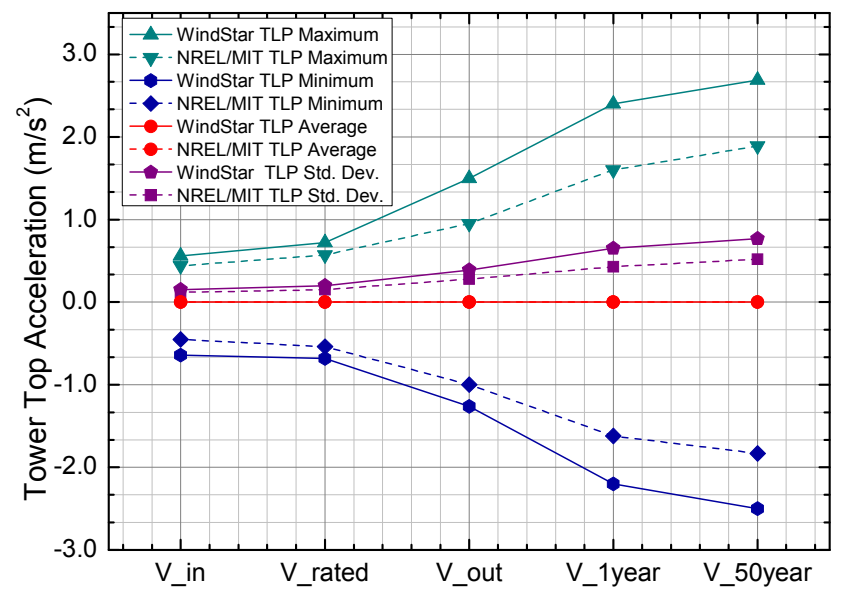

(c)

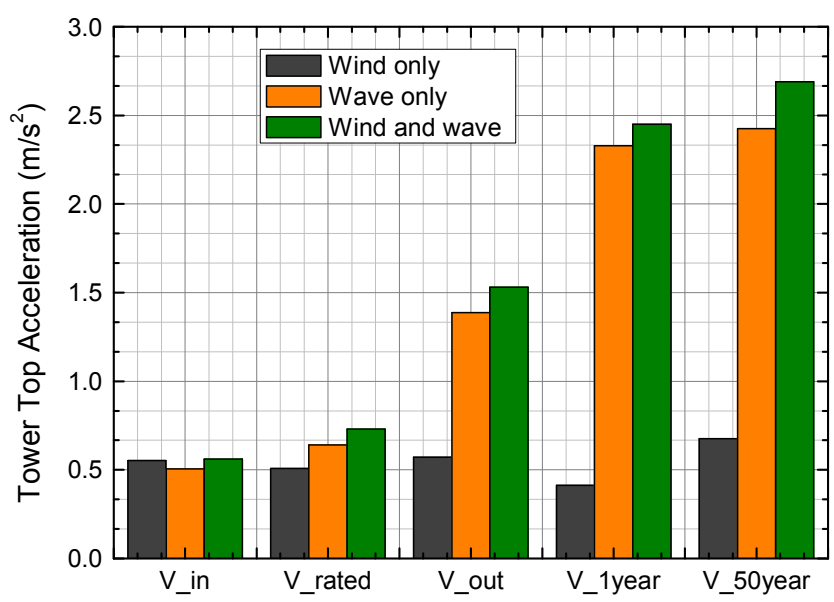

(e)

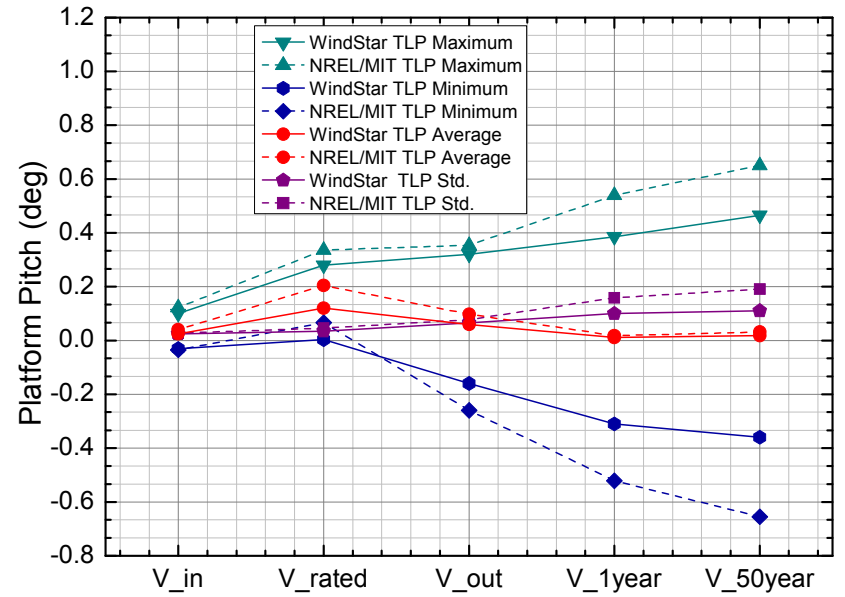

(b)

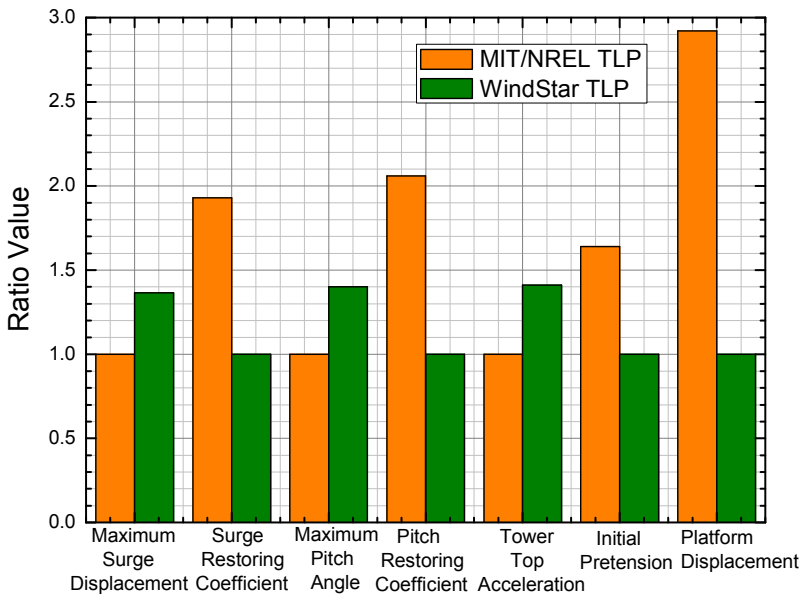

(d)

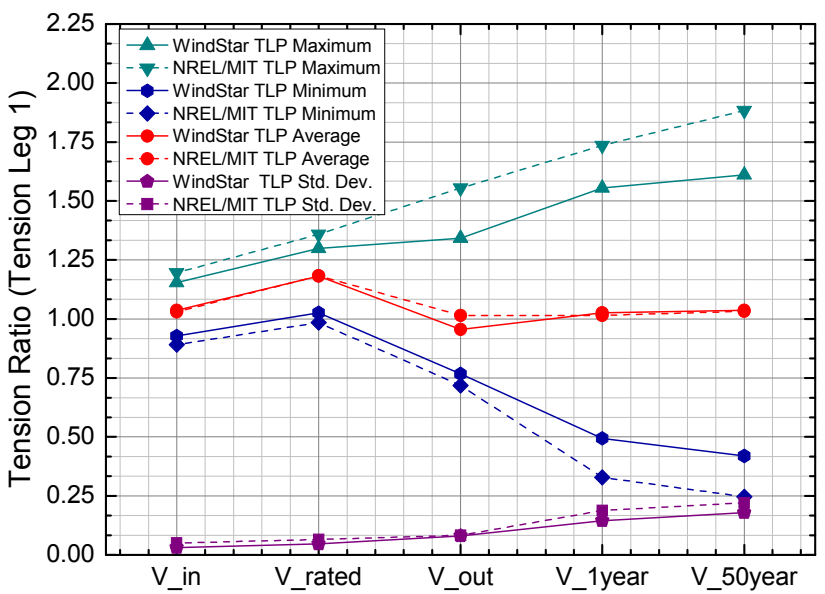

(f) 


\section{Conclusions}

In this study the WindStar TLP was proposed for the NREL offshore 5-MW baseline wind turbine. The general arrangement, main structure and mooring system were designed based on the assumed design framework. Polyester ropes were adopted for the tension mooring system. The proposed WindStar TLP has been investigated using hydrodynamic analysis, natural frequency analysis with a detailed FE model and fully coupled dynamic analysis. As a result, the complete system is free from resonance with the rotor excitations. The elasticity of the turbine system and TLP foundation has a significant influence on predicting natural frequencies of the FWT. The statistical results from the dynamic response time series show that the design requirements are satisfied. Comparisons between the WindStar TLP and MIT/NREL TLP have been carried out. With a lighter and smaller structure, WindStar TLP showed satisfactory performance, thus the proposed concept can be identified as having significant potential for further development. Further work will be carried out to optimise the structural dimensions. Additional load cases will be analysed according to IEC-61400-3 requirements, a scaled model test will be performed in a wave tank, and the structural integrity of the WindStar TLP foundation will be assessed.

\section{Acknowledgements}

The authors gratefully acknowledge the help of Jason Jonkman at the National Renewable Energy Laboratory (Golden, CO, USA) for providing the reference site data.

\section{References}

1. Robertson, A.; Jonkman, J.M. Loads Analysis of Several Offshore Floating Wind Turbine Concepts; Technical Report NREL/TP-5000-50539; National Renewable Energy Laboratory: Golden, CO, USA, 2011.

2. Henderson, A.R.; Witcher, D.; Morgan, C.A. Floating support structures enabling new markets for offshore wind energy. In Proceedings of the European Wind Energy Conference, Marseille, France, 16-19 March 2009.

3. Wang, C.M.; Utsunomiya, T.; Wee, S.C.; Choo, Y.S. Research on Floating wind turbines: A literature survey. IES J. Part A Civil Struct. Eng. 2010, 3, 267-277.

4. Cordle, A. State-of-the-art in design tools for floating offshore wind turbines, 2010. Available online: http://www.upwind.eu/pdf/UpWind_WP4_D4.3.5_Floating\%20design\%20tools.pdf (accessed on 25 July 2012).

5. Nielsen, F.G.; Hanson, T.D.; Skaare, B. Integrated dynamic analysis of floating offshore wind turbine. In Proceedings of OMAE 25th International Conference on Offshore Mechanics and Arctic Engineering, Hamburg, Germany, 4-9 June 2006.

6. Roddier, D.; Cermelli, C.; Aubault, A.; Weinstein, A. WindFloat: A floating foundation for offshore wind turbines. J. Renew. Sustain. Energy 2010, 2, 104-138.

7. Suzuki, K.; Yamaguchi, H.; Akase, M.; Imakita, A.; Ishihara, T.; Fukumoto, Y.; Oyama, T. Initial design of tension leg platform for offshore wind farm. J. Fluid Sci. Technol. 2011, 6, 372-381.

8. Ren, N.; Li, Y.; Ou, J. The effect of additional mooring chains on the motion performance of a floating wind turbine with a tension leg platform. Energies 2012, 5, 1135-1149. 
9. Matha, D. Model Development and Load Analysis of an Offshore Wind Turbine on a Tension Leg Platform, with a Comparison to Other Floating Turbine Concepts; Technical Report NREL/SR-500-45891; National Renewable Energy Laboratory: Golden, CO, USA, 2010.

10. Moon, W.L., III; Nordstrom, C.J. Tension leg platform turbine: A unique integration of mature technologies. In Proceedings of the 16th Offshore Symposium, Houston, TX, USA, 9 February 2010.

11. Jonkman, J.M. Dynamics Modeling and Loads Analysis of an Offshore Floating Wind Turbine. Ph.D. Thesis, University of Colorado, Boulder, CO, USA, 2007.

12. Jonkman, J.M.; Matha, D. Dynamics of offshore floating wind turbines-analysis of three concepts. Wind Energy 2011, 14, 557-569.

13. Fischer, T.; de Vries, W.; Schmidt, B. Upwind design basis, 2010. Available online: http://www.upwind.eu/pdf/WP4_DesignBasis.pdf (accessed on 11 August 2012).

14. IEC Technical Committee 88. Wind Turbines-Part 3: Design Requirements for Offshore Wind Turbines; Technical Report 61400-3 ed.1.0; IEC: Geneva, CH, USA, 2008.

15. Jonkman, J.; Butterfield, S.; Musial, W.; Scott, G. Definition of a 5-MW Reference Wind Turbine for Offshore System Development; Technical Report NREL/TP-500-38060; National Renewable Energy Laboratory: Golden, CO, USA, 2009.

16. American Petroleum Institute. Bulletin on Stability Design of Cylindrical Shells, 3rd ed.; American Petroleum Institute (API): Washington, DC, USA, 2004.

17. American Bureau of Shipping. Rules for Building and Classing Mobile Offshore Drilling Units, Part 3: Hull Construction and Equipment; American Bureau of Shipping (ABS): Houston, TX, USA, 2012.

18. Bexco n.v. Polyester and Dyneema ${ }^{\circledR}$ Mooring Ropes Manual; 2004. Available online: http://www.offshoremoorings.org/moorings/Downloads/deepropemanual.pdf (accessed on 12 August 2012).

19. Withee, J.E. Fully Coupled Dynamic Analysis of a Floating Wind Turbine System. Ph.D. Thesis, Massachusetts Institute of Technology, Cambridge, MA, USA, 2004.

20. Det Norske Veritas. Wave Analysis by Diffraction and Morison Theory (WADAM); SESAM User's Manual, Det Norske Veritas (DNV): Høvik, Norway, 1994.

21. Jonkman, J.M.; Buhl, M.L., Jr. FAST User's Guide; Technical Report NREL/EL-500-38230; National Renewable Energy Laboratory: Golden, CO, USA, 2005.

22. Bae, Y.H.; Kim M.H.; Im, S.W. Effects of tower elasticity and aero-loading in aero-elasticcontrol-floater-mooring coupled dynamic analysis for a TLP-type FOWT. In Proceedings of the Twenty-second International Offshore and Polar Engineering Conference, Rhodes, Greece, 17-22 June 2012.

23. Grant, S. MSC/NASTRAN Basic Dynamic Analysis User's Guide; The MacNeal Schwendler Corporation: Los Angeles, CA, USA, 1997; pp. 36-86.

24. Jonkman, B.J.; Buhl, M.L., Jr. TurbSim User's Guide; Technical Report NREL/TP-500-41136; National Renewable Energy Laboratory: Golden, CO, USA, 2007.

(C) 2012 by the authors; licensee MDPI, Basel, Switzerland. This article is an open access article distributed under the terms and conditions of the Creative Commons Attribution license (http://creativecommons.org/licenses/by/3.0/). 